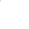

Supporting information for:

Exposure to waterborne $\mathrm{nTiO}_{2}$ reduces fertilization success and increases polyspermy in a bivalve mollusc: a threat to

\title{
population recruitment
}

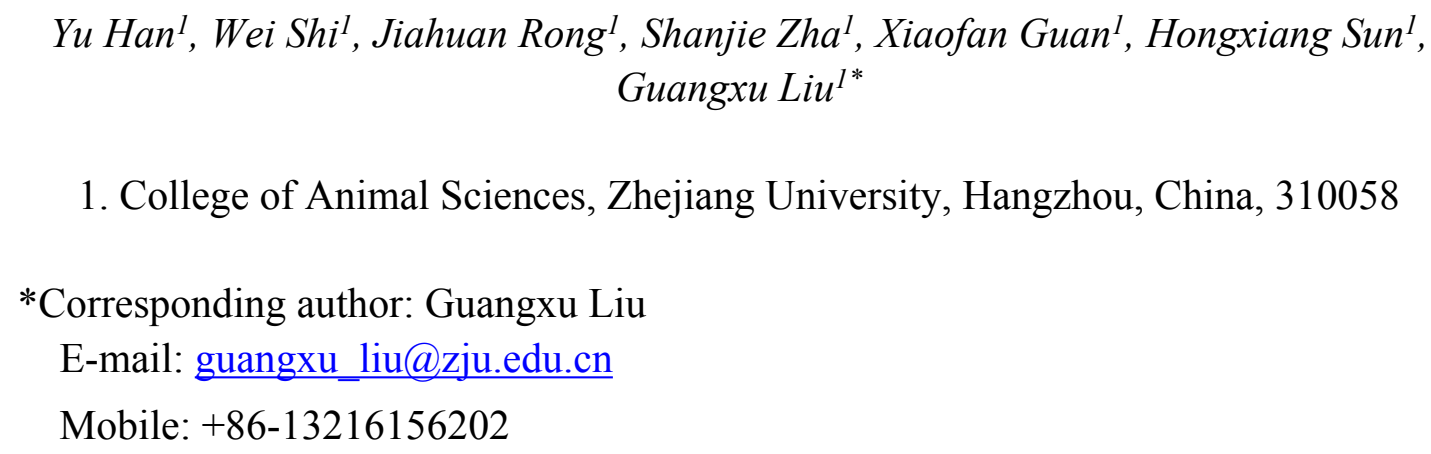

Contents (3 Pages, 2 Figures, 2 Tables)

Intensity of $\mathrm{nTiO}_{2}$.

TEM micrograph of the $\mathrm{nTiO}_{2}$ samples.

Physicochemical properties of $\mathrm{nTiO}_{2}$ used in the present study

The values of fertilization, polyspermy, gamete fusion efficiency and DNA damage.

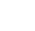
. . . 5 6 


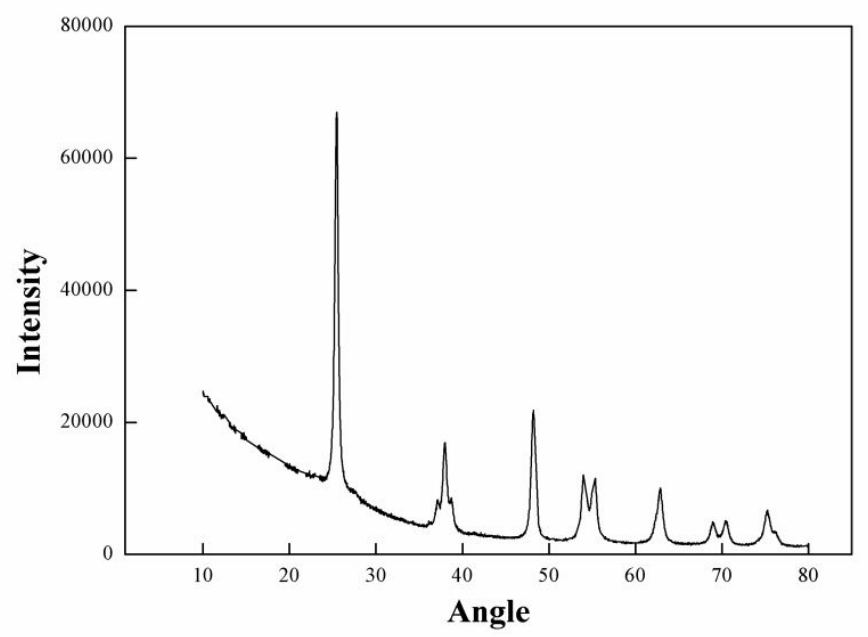

38

39

40

41

51

52

53

54

55

56

57

58

59
Figure S1. Intensity of $\mathbf{n T i O}_{2}$.

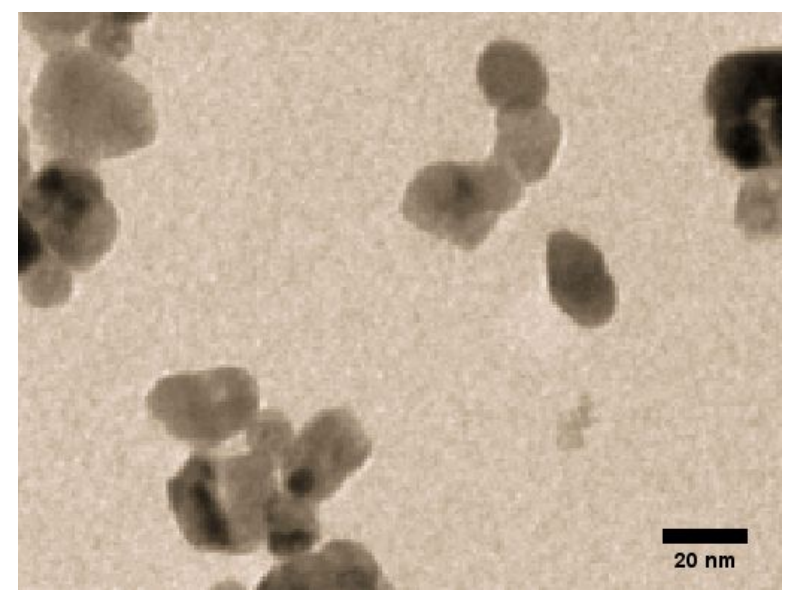

Figure S2. TEM micrograph of the $\mathrm{nTiO}_{2}$ samples. 


\begin{tabular}{lc}
\hline Property & $\mathrm{TiO}_{2} \mathrm{NPs}$ \\
\hline Average diameter & $20.49 \pm 3.51 \mathrm{~nm}$ \\
BET surface area & $61.75 \mathrm{~m}^{2} \mathrm{~g}^{-1}$ \\
Crystal structure & Anatase \\
\hline
\end{tabular}

61

62

63

64

Table S2. The values (mean $\pm \mathrm{SD}$ ) of fertilization success, polyspermy rate, gamete fusion

65

efficiency and DNA damage content of each experimental group. Mean values that do not

66 share the same superscript are significantly different at $p<0.05$.

\begin{tabular}{|c|c|c|c|c|c|}
\hline Treatment types & $\begin{array}{c}\text { Endpoint } \\
\text { investigated }\end{array}$ & Control & Bulk & $10 \mu \mathrm{g} / \mathrm{L}$ & $100 \mu \mathrm{g} / \mathrm{L}$ \\
\hline \multirow{2}{*}{ Oocytes treated } & Fertilization rate & $91.82 \pm 2.41^{\mathrm{a}}$ & $90.18 \pm 3.20^{\mathrm{a}}$ & $77.41 \pm 6.01^{\mathrm{b}}$ & $66.57 \pm 3.96^{\mathrm{c}}$ \\
\hline & Polyspermy rate & $3.03 \pm 1.54^{\mathrm{c}}$ & $3.86 \pm 1.34^{\mathrm{c}}$ & $8.92 \pm 3.38^{\mathrm{b}}$ & $13.73 \pm 3.70^{\mathrm{a}}$ \\
\hline \multirow{2}{*}{ Sperm treated } & Fertilization rate & $92.83 \pm 1.42^{\mathrm{a}}$ & $91.50 \pm 1.38^{\mathrm{a}}$ & $87.37 \pm 1.99^{b}$ & $73.39 \pm 3.61^{\mathrm{c}}$ \\
\hline & Polyspermy rate & $1.40 \pm 0.08^{\mathrm{c}}$ & $1.26 \pm 0.12^{\mathrm{c}}$ & $3.12 \pm 0.22^{b}$ & $4.44 \pm 0.35^{\mathrm{a}}$ \\
\hline \multirow{2}{*}{ Both gamete treated } & Fertilization rate & $91.66 \pm 2.16^{\mathrm{a}}$ & $90.06 \pm 2.10^{\mathrm{a}}$ & $74.83 \pm 7.30^{\mathrm{b}}$ & $48.03 \pm 9.20^{\mathrm{c}}$ \\
\hline & Polyspermy rate & $3.04 \pm 0.65^{\mathrm{c}}$ & $3.63 \pm 0.52^{\mathrm{c}}$ & $10.38 \pm 1.59^{\mathrm{b}}$ & $20.30 \pm 2.33^{\mathrm{a}}$ \\
\hline Oocytes treated & Gamete fusion & $0.029 \pm 0.003^{\mathrm{a}}$ & $0.027 \pm 0.003^{\mathrm{a}}$ & $0.018 \pm 0.004^{\mathrm{b}}$ & $0.014 \pm 0.001^{\mathrm{c}}$ \\
\hline Sperm treated & Gamete fusion & $0.030 \pm 0.002^{\mathrm{a}}$ & $0.028 \pm 0.002^{\mathrm{a}}$ & $0.024 \pm 0.002^{\mathrm{b}}$ & $0.018 \pm 0.002^{\mathrm{c}}$ \\
\hline Both gamete treated & Gamete fusion & $0.029 \pm 0.003^{\mathrm{a}}$ & $0.028 \pm 0.003^{\mathrm{a}}$ & $0.017 \pm 0.003^{\mathrm{b}}$ & $0.013 \pm 0.003^{\mathrm{c}}$ \\
\hline Oocytes treated & DNA damage extent & $1.00 \pm 0.24^{\mathrm{c}}$ & $0.98 \pm 0.18^{c}$ & $3.39 \pm 0.63^{b}$ & $15.72 \pm 4.09^{\mathrm{a}}$ \\
\hline Sperm treated & DNA damage extent & $1.00 \pm 0.22^{\mathrm{c}}$ & $1.04 \pm 0.45^{\mathrm{c}}$ & $7.61 \pm 1.86^{\mathrm{b}}$ & $15.68 \pm 1.10^{\mathrm{a}}$ \\
\hline
\end{tabular}

